\title{
Stress Analysis at a Bi-Material Interface Crack-tip
}

\author{
G.A. Papadopoulos*
}

National Technical University of Athens, Department of Engineering Science, Section of Mechanics, GR-157 73 , Zografou campus, Athens, Greece

\begin{abstract}
The optical methods of Caustics, Photoelasticity and Isopachics for the evaluation of the stress intensity factors and the distribution of the principal stresses at a bi-material interface crack-tip, were proposed. The caustics, isochromatic and isopachic fringes are developed from the stress field which results from a stress function $\mathrm{X}(\mathrm{r}, \theta)$. When the crack-tip, which is perpendicular to interface, is at the interface of the bi-material, the caustics, isochromatic and isopachic fringes depend on the properties of the two materials. So, the caustic, isochromatic and isopachic fringes are divided into two branches, which present a jump of values at the interface. The shape and size of the two branches of caustics, isochromatic and isopachic fringes depend mainly on the elastic modulus and Poisson's ratio of the two materials. From the caustics the stress intensity factor $\mathrm{K}_{\mathrm{I}}$ can be calculated, while from the combination of the isochromatic and the isopachic fringes, the principal stresses $\sigma_{1}, \sigma_{2}$ can be theoretically and experimentally calculated. The optical evaluation of the stress intensity factors and the distribution of the principal stresses from isochromatic and isopachic fringes is presented. The stress intensity factors and the principal stresses at the bi-material interface crack-tip, were experimentally determined using the caustics and the combination photoelastic and isopachic measurements. The size and shape of the crack-tip caustics, isochromatic and isopachic fringes, at a bi-material interface under static load, were theoretically and experimentally studied.
\end{abstract}

\section{INTRODUCTION}

The experimental method of transmitted caustics was first developed by Manogg [1] while, the experimental method of reflected caustics was developed by Theocaris [2]. The experimental method of caustics, which is based on the laws of geometrical optics, transforms the stress singularity into an optical singularity. This optical singularity gives much information for the evaluation of the stress field. According to the method of caustics, a coherent light beam from a laser impinges normally on the specimen in the vicinity of the crack tip, and the reflected rays are received on a reference screen at some distance from the specimen. When a certain load is applied to the specimen, the reflected light rays in the vicinity of the crack tip, where there is an abrupt thickness variation due to the existence of a singularity, are scattered and when projected on a reference screen placed at some distance from the specimen are concentrated along a curve, the so-called caustic [3]. The optical method of reflected caustics, as it has been developed during the last thirty five years, was extensively applied to various elastic problems containing singularities and especially to the problems with cracked plates, which were made of isotropic or birefringent materials [4].

The study of the behavior of a transverse crack, propagating through the mesophase of composites, has become a subject of great interest. The problem of crack propagation in a duplex plate was studied by Williams et al. [5-9] and later was approached by Dally and Kobayashi [10], by means of dynamic photoelasticity. Theocaris et al. [11-

*Address correspondence to this author at the National Technical University of Athens, Department of Engineering Science, Section of Mechanics, GR-157 73, Zografou campus, Athens, Greece; E-mail: gpad@central.ntua.gr
13], have studied the influence of both the mesophase and the material characteristics of either phase, in biphase plates consisting of different materials, on the stress distribution around the crack tip. They have extended their study to the magnitude and the variation of the crack propagation velocities during fracture in duplex plates under dynamic loading [14]. Also, Theocaris et al. [15,16], have studied the influence of the hard or soft fiber and the mesophase layers in a soft-hard-soft or hard-soft-hard combination of biphase plate subjected to a dynamic tensile load, on the fracture mode and bifurcation process in both phases. Also, theoretical studies on this subject were carried out by Gdoutos et al. [17-19], Theotokoglou et al. [20-22]. The study of size and shape of the crack-tip caustics at a bimaterial interface, was carried out by Papadopoulos et al. $[22,23]$.

This work is an attempt to study the size and shape of crack-tip caustics, isochromatic and isopachic fringes, and the estimation of the principal stresses and its contour from the combination of the isochromatic and the isopachic fringes, at a bi-material interface under static load.

\section{Stress-Field Around The Crack-Tip}

Two plates of moduli $\mathrm{E}_{1}$ and $\mathrm{E}_{2}$ and Poisson's ratios $v_{1}$ and $v_{2}$, are perfectly bonded along their common interface (see Fig. (1)). In plate (1), there is a crack perpendicular to the interface. The crack-tip is placed exactly at the interface of the two plates. To study this problem the Airy stress function $\mathrm{X}(\mathrm{r}, \theta)$ used by Zak and Williams [5], is taken into account. This stress function is of form:

$$
X(r, \theta)=r^{\lambda+1} F(\theta)
$$

with: 
$F(\theta)=\alpha \sin (\lambda+1) \theta+b \cos (\lambda+1) \theta+$

$c \sin (\lambda-1) \theta+d \cos (\lambda-1) \theta$

where $\alpha, b, c, d$ are constants and $\lambda$ takes values between 0 and 1 , which depends on the ratio $E_{12}=E_{1} / E_{2}$ of the two plates moduli $[22,23]$.

From the stress function (1) the polar stresses at the crack-tip are taken:

$\sigma_{r}=-\lambda r^{\lambda-1}\left[\begin{array}{l}\alpha(\lambda+1)|\sin (\lambda+1) \theta|+ \\ b(\lambda+1)|\cos (\lambda+1) \theta| \\ +c(\lambda-3)|\sin (\lambda-1) \theta|+ \\ d(\lambda-3)|\cos (\lambda-1) \theta|\end{array}\right]$

$\sigma_{\theta}=\lambda(\lambda+1) r^{\lambda-1}\left[\begin{array}{l}\alpha|\sin (\lambda+1) \theta|+ \\ b|\cos (\lambda+1) \theta| \\ +c|\sin (\lambda-1) \theta|+ \\ d|\cos (\lambda-1) \theta|\end{array}\right]$

$\tau_{r \theta}=-\lambda r^{\lambda-1}\left[\begin{array}{l}\alpha(\lambda+1)|\cos (\lambda+1) \theta|- \\ b(\lambda+1)|\sin (\lambda+1) \theta| \\ +c(\lambda-1)|\cos (\lambda-1) \theta|- \\ d(\lambda-1)|\sin (\lambda-1) \theta|\end{array}\right]$

The boundary conditions of the problem are written as:

$$
\begin{aligned}
& \tau_{r \theta_{1}}=0 \text { and } \sigma_{\theta_{1}}=0 \text { for } \theta_{1}=\frac{\pi}{2} \\
& \tau_{r \theta_{2}}=0 \quad \text { and } \quad v_{2}=0 \text { for } \theta_{2}=\frac{\pi}{2}
\end{aligned}
$$

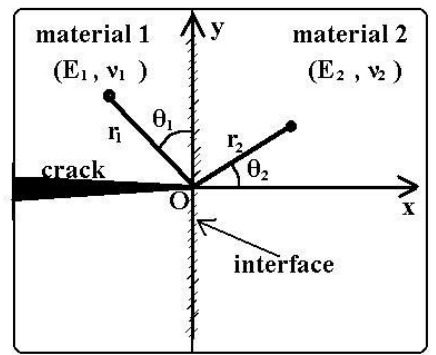

Fig. (1). Geometry of bi-material plate.

$\sigma_{\theta_{1}}=\sigma_{\theta_{2}}, \quad \tau_{r \theta_{1}}=\tau_{r \theta_{2}}, \quad u_{1}=u_{2}$,

$v_{1}=v_{2}$ for $\theta_{1}=0$ and $\theta_{2}=\frac{\pi}{2}$

where $u_{1,2}, v_{1,2}$ are the displacement components.

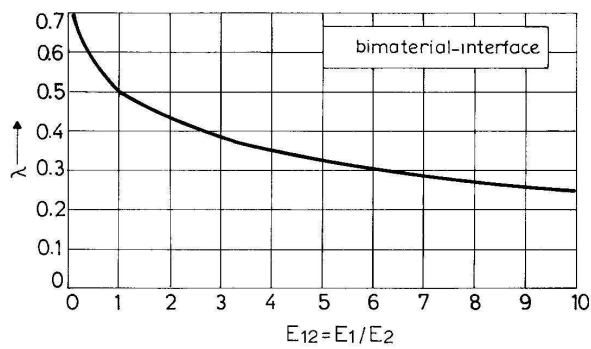

Fig. (2). Variation of $\lambda$ versus ratio $E_{12}=E_{1} / E_{2}$ for Poisson's ratios $v_{1}=v_{2}=0.30$.
From the boundary conditions (6) the values of the $\lambda$ can be determined. Fig. (2) presents the variation of $\lambda$ versus the ratio $E_{12}$ of the moduli of the plates. Various values of $\lambda$ according to ratio $E_{12}$ and Poisson's ratios $v_{1}, v_{2}$ are given in Table 1.

Table 1. Values of $\lambda$ for Various Values of $E_{12}$ and $v_{1}, v_{2}$

\begin{tabular}{|l|l|l|l|}
\hline \multicolumn{1}{|c|}{$\mathbf{E}_{\mathbf{1 2}}$} & $\mathbf{v}_{\mathbf{1}}$ & $\mathbf{v}_{\mathbf{2}}$ & $\boldsymbol{\lambda}$ \\
\hline \hline 1.2142 & 0.34 & 0.36 & 0.48 \\
\hline 0.82353 & 0.36 & 0.34 & 0.5192 \\
\hline 0.10 & 0.30 & 0.30 & 0.6966 \\
\hline 0.1428 & 0.30 & 0.30 & 0.6764 \\
\hline 0.2016 & 0.30 & 0.30 & 0.6525 \\
\hline 0.336 & 0.36 & 0.34 & 0.603 \\
\hline 1.00 & 0.30 & 0.30 & 0.50 \\
\hline 2.97 & 0.34 & 0.36 & 0.3803 \\
\hline 4.96 & 0.30 & 0.30 & 0.323 \\
\hline 7.03 & 0.30 & 0.30 & 0.2852 \\
\hline 9.985 & 0.30 & 0.30 & 0.249 \\
\hline
\end{tabular}

\section{Theory of Caustics}

The deflection of light, either reflected from, or passing through a generic point $\mathrm{P}$ of the plate in the vicinity of the crack-tip, is given by the deviation vector $\mathbf{W}$, which, for an optically isotropic material, is expressed by [1-3]:

$\mathbf{W}_{r, t, f}=X_{r, t, f} \mathbf{i}+Y_{r, t, f} \mathbf{j}=\mathbf{r}+\mathbf{w}_{r, t, f}$

with:

$\mathbf{w}_{r, t, f}=-\varepsilon z_{0} t c_{r, t, f} \operatorname{grad}_{x, y}\left(\sigma_{r}+\sigma_{\theta}\right)$,
$\mathbf{r}=r \cos \theta \mathbf{i}+r \sin \theta \mathbf{j}$

where $\varepsilon$ is a multiplying factor, which is equal to unity, for reflected from the front (f) face or transmitted (t) light rays and equal to 2 for light rays reflected from the rear (r) face of the plate, $c_{r, t, f}$ are the stress-optical constants for the material, $\mathrm{t}$ is the thickness of the plate and $z_{0}$ is the distance between the plate and the reference screen. The stress-optical constant $c_{f}=v_{1,2} / E_{1,2}$ for the materials 1 and 2 , respectively.

The sum of the stresses $\sigma_{r}$ and $\sigma_{\theta}$ (Eqs (3) and (4)) is:

$\sigma_{r}+\sigma_{\theta}=r^{\lambda-1}\left[(\lambda+1)^{2} F(\theta)+F^{\prime \prime}(\theta)\right]$

The grad of the sum of the stresses is:

$$
\begin{aligned}
& \operatorname{grad}_{x, y}\left(\sigma_{r}+\sigma_{\theta}\right)= \\
& (\lambda-1) r^{\lambda-2}\left[(\lambda+1)^{2} F(\theta)+F^{\prime \prime}(\theta)\right](\cos \theta \mathbf{i} \\
& +\sin \theta \mathbf{j})+r^{\lambda-2}\left[(\lambda+1)^{2} F^{\prime}(\theta)+F^{\prime \prime}(\theta)\right] \\
& (-\sin \theta \mathbf{i}+\cos \theta \mathbf{j})
\end{aligned}
$$

and from the relations (7) and (8) the parametric equations of the caustics (r) and (t) ((r) is the caustic which is formed by the reflected light rays from the rear face of the plate and $(t)$ is the caustic which is formed by the transmitted light rays through the plate) are obtained as [22]: 


$$
\begin{gathered}
X_{r, t}=\lambda_{m} r_{01,2}\left\{\begin{array}{l}
\cos \theta_{1,2}-\frac{1}{(\lambda-2) \sqrt{c_{2}^{2}+d_{2}^{2}}} \\
{\left[\begin{array}{l}
c_{2} \sin (\lambda-2) \theta_{1,2}+ \\
d_{2} \cos (\lambda-2) \theta_{1,2}
\end{array}\right]}
\end{array}\right\} \\
Y_{r, t}=\lambda_{m} r_{01,2}\left\{\begin{array}{l}
\sin \theta_{1,2}-\frac{1}{(\lambda-2) \sqrt{c_{2}^{2}+d_{2}^{2}}} \\
{\left[\begin{array}{l}
c_{2} \cos (\lambda-2) \theta_{1,2}- \\
d_{2} \sin (\lambda-2) \theta_{1,2}
\end{array}\right]}
\end{array}\right\}
\end{gathered}
$$

where $\lambda_{m}$ is the magnification factor of the optical set-up, which is given by:

$\lambda_{m}=\frac{z_{0} \pm z_{i}}{z_{i}}$

where $z_{i}$ is the distance between plate and focus of the light beam, $(+)$ for the reflected and (-) for the transmitted, through the plate rays.

The parametric equations of the caustic (f) ((f) is the caustic which is formed by the reflected light rays from the front face of the plate) are:

$$
\begin{gathered}
X_{f}=\lambda_{m} r_{01,2}\left\{\begin{array}{l}
\cos \theta_{1,2}+\frac{1}{(\lambda-2) \sqrt{c_{2}^{2}+d_{2}^{2}}} \\
{\left[\begin{array}{l}
c_{2} \sin (\lambda-2) \theta_{1,2}+ \\
d_{2} \cos (\lambda-2) \theta_{1,2}
\end{array}\right]}
\end{array}\right\} \\
Y_{f}=\lambda_{m} r_{01,2}\left\{\begin{array}{l}
\sin \theta_{1,2}+\frac{1}{(\lambda-2) \sqrt{c_{2}^{2}+d_{2}^{2}}} \\
{\left[\begin{array}{l}
c_{2} \cos (\lambda-2) \theta_{1,2}- \\
d_{2} \sin (\lambda-2) \theta_{1,2}
\end{array}\right]}
\end{array}\right\}
\end{gathered}
$$

The radius of the initial curve of the caustics is:

$$
r_{01,2}=\left[\begin{array}{l}
4 \lambda(\lambda-1)(\lambda-2) C_{r, t, f} \\
\sqrt{c_{1,2}^{2}+d_{1,2}^{2}}
\end{array}\right]^{1 /(3-\lambda)}
$$

with:

$$
C_{r, t, f}=-\frac{\varepsilon z_{0} t c_{r, t, f}}{\lambda_{m}}
$$

where the indices 1,2 are the materials 1 and 2 of the bimaterial plate are represented. The polar coordinate $\theta_{1}$ takes values in the region $[\pi / 2, \pi] \mathrm{U}[-\pi,-\pi / 2]$ (material 1$)$ and $\theta_{2}$ takes values in the region $[-\pi / 2,+\pi / 2]$ (material 2$)$.

The constants $\alpha_{1,2}, b_{1,2}, c_{1,2}, d_{1,2}$, which are calculated by the boundary conditions (6), are given by the relations:

$\alpha_{2}=c_{2}=0, \quad d_{2}=$ arbitrary cons $\tan t$

$\alpha_{1}=\left\{E_{12}(\lambda-1)\left[b_{2}\left(v_{2}+1\right)(\lambda+1)-d_{2}\left(\lambda\left(v_{2}\right.\right.\right.\right.$

$\left.\left.+1)+3-v_{2}\right)\right]-\left[b_{2}(\lambda+1)+d_{2}(1-\lambda)\right]\left[v_{1}(\lambda-1)\right.$

$$
\begin{aligned}
& b_{1}=-\left\{E _ { 1 2 } \left[b_{2}\left(\lambda\left(v_{2}+1\right)+v_{2}+1\right)-d_{2}\left(\lambda \left(v_{2}\right.\right.\right.\right. \\
& \left.\left.+1)+v_{2}-3\right)\right]-v_{1}(\lambda+1)\left(b_{2}-d_{2}\right)+b_{2}(\lambda-3) \\
& \left.+d_{2}(3-\lambda)\right\} 0.25 \sin (\lambda \pi / 2) \\
& c_{1}=-\left\{E _ { 1 2 } \left[b_{2}\left(v_{2}+1\right)(\lambda+1)-d_{2}\left(\lambda\left(v_{2}+1\right)\right.\right.\right. \\
& \left.\left.+3-v_{2}\right)\right]-\left[b_{2}(\lambda+1)+d_{2}(1-\lambda)\right]\left(v_{1}\right. \\
& +1)\} 0.25 \cos (\lambda \pi / 2) \\
& d_{1}=\left\{E _ { 1 2 } \left[b_{2}\left(v_{2}+1\right)(\lambda+1)-d_{2}\left(\lambda\left(v_{2}+1\right)+v_{2}\right.\right.\right. \\
& \left.-3)]-(\lambda+1)\left(b_{2}-d_{2}\right)\left(v_{1}+1\right)\right\} 0.25 \sin (\lambda \pi / 2) \\
& b_{2}=\left\{d _ { 2 } \left[\left[E_{12}\left[\lambda\left(3 v_{2}-5\right)+v_{2}-3\right]-\left[v_{1}(3 \lambda\right.\right.\right.\right. \\
& +1)+1-\lambda]] \cos (\lambda \pi)+\left[v_{1}\left(2 \lambda^{2}+\lambda+1\right)\right. \\
& +(\lambda-1)(2 \lambda+3)]-E_{12}\left[2 \lambda^{2}\left(v_{2}+1\right)+\lambda\left(v_{2}+1\right)\right. \\
& \left.\left.\left.+v_{2}-3\right]\right]\right\} /\left\{\left[\left[E_{12}\left(v_{2}+1\right)\right.\right.\right. \\
& \left.+3-v_{1}\right] \cos (\lambda \pi)-(2 \lambda+1)\left[E_{12}\left(v_{2}+1\right)\right. \\
& \left.\left.\left.-\left(v_{1}+1\right)\right]\right](\lambda+1)\right\}
\end{aligned}
$$

The variables $\mathrm{E}_{12}, v_{1}, v_{2}$ are dependent on the materials while, the variable $\mathrm{d}_{2}$ depends on the conditions of the experiment and mainly on the stress of loading.

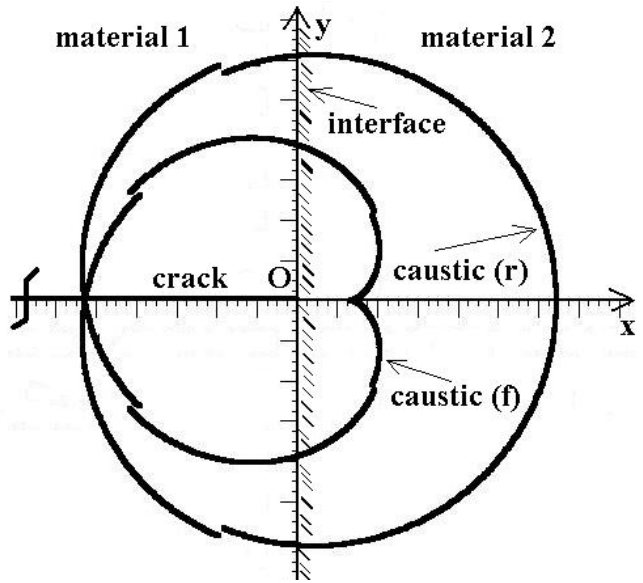

Fig. (3). Theoretical caustics for $E_{12}=1.2142, v_{1}=0.34, v_{2}=0.36$ and $\lambda=0.48$ (Plexiglas 1-Lexan 2).

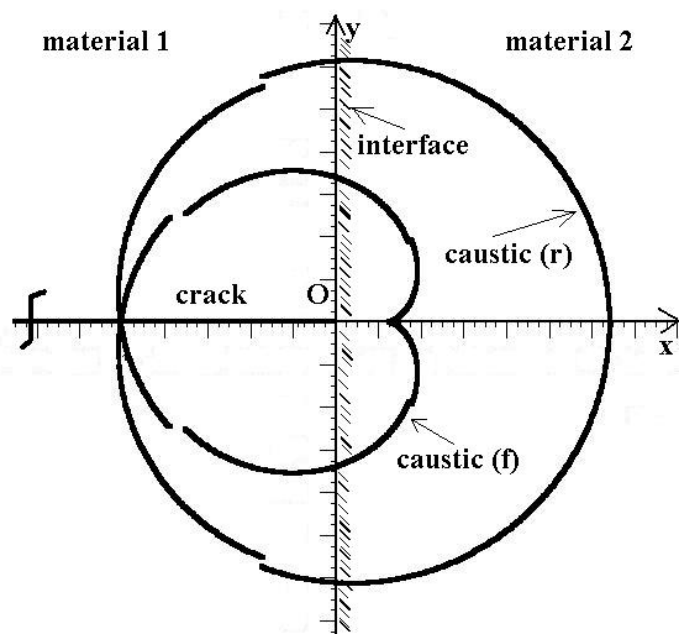

Fig. (4). Theoretical caustics for $E_{12}=0.82353, v_{1}=0.36, v_{2}=0.34$ and $\lambda=0.5192$ (Lexan 1-Plexiglas 2). 
For Plexiglas (PMMA), with $\mathrm{E}_{1}=3.4 \mathrm{GPa}$ and $v_{1}=0.34$, as material 1, and Lexan (PCBA), with $\mathrm{E}_{2}=3.8 \mathrm{GPa}$ and $v_{2}$ $=0.36$, as material 2 (Fig. (1)), the theoretical caustics at the crack-tip, at the bi-material interface were plotted according to equations (11)-(23). Fig. (3) presents the plotted caustics, caustic (r) and caustic (f), for Plexiglas 1 - Lexan 2 bimaterial plate with $\mathrm{E}_{12}=1.2142, v_{1}=0.34, v_{2}=0.36, \lambda=0.48$, $\mathrm{b}_{2}=0.353 \mathrm{~d}_{2}, \mathrm{c}_{1}=0.826 \mathrm{~d}_{2}, \mathrm{~d}_{1}=0.78 \mathrm{~d}_{2}, \mathrm{c}_{2}=0$ and $\mathrm{d}_{2}=1$. The size of the caustic (r) depends on the initial curve radius, which further depends on the stress optical constants $c_{r, t, f}$. The jump of the values at the interface depends on the polar coordinate $\theta$ of the initial curve. This jump, which is corresponded to $\theta= \pm \pi / 2$ of the initial curve, is not placed at the interface because the values of the caustic are deviated (relation (8)).

Fig. (4) presents the plotted caustics, caustic (r) and caustic (f), for Lexan 1 - Plexiglas 2 bi-material plate with $\mathrm{E}_{12}=0.82353, \quad v_{1}=0.36, \quad v_{2}=0.34, \quad \lambda=0.5192, \quad b_{2}=0.316 \mathrm{~d}_{2}$, $\mathrm{c}_{1}=0.607 \mathrm{~d}_{2}, \mathrm{~d}_{1}=0.648 \mathrm{~d}_{2}, \mathrm{c}_{2}=0$ and $\mathrm{d}_{2}=1$.

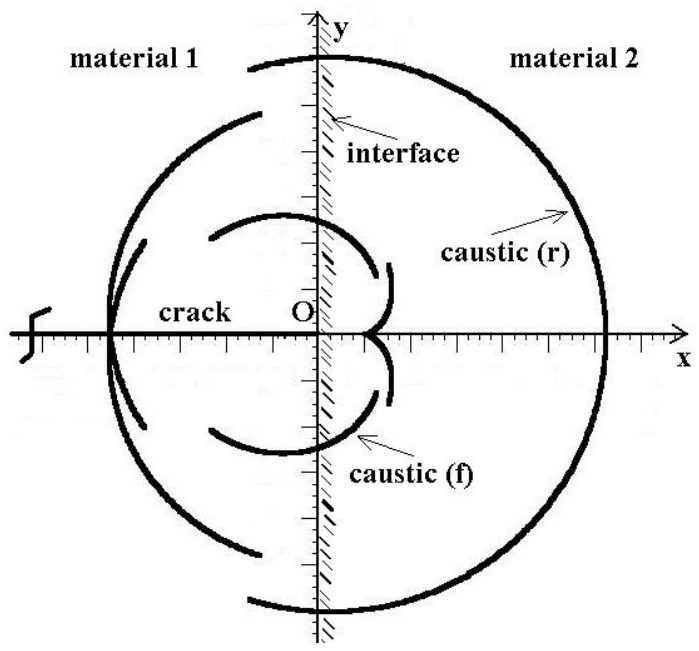

Fig. (5). Theoretical caustics for $\mathrm{E}_{12}=0.336, v_{1}=0.36, v_{2}=0.34$ and $\lambda=0.6003$ (ductile 1-brittle 2).

Fig. (5) presents the plotted caustics, caustic (r) and caustic (f), for ductile material 1 - brittle material 2 bimaterial plate with $\mathrm{E}_{12}=0.336, v_{1}=0.36, v_{2}=0.34, \lambda=0.603$, $\mathrm{b}_{2}=0.275 \mathrm{~d}_{2}, \mathrm{c}_{1}=0.307 \mathrm{~d}_{2}, \mathrm{~d}_{1}=0.487 \mathrm{~d}_{2}, \mathrm{c}_{2}=0$ and $\mathrm{d}_{2}=1$.

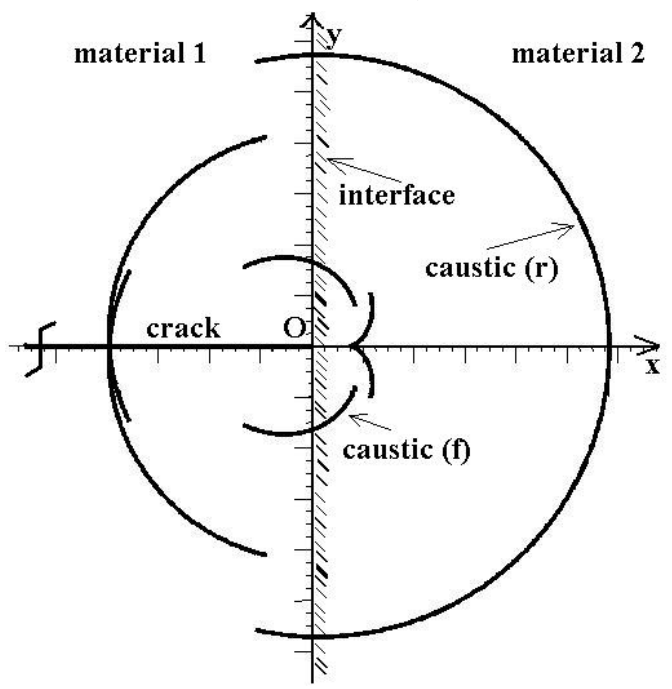

Fig. (6). Theoretical caustics for $E_{12}=0.10, v_{1}=v_{2}=0.30$ and $\lambda=0.6966$ (ductile 1-brittle 2).
Fig. (6) presents the plotted caustics, caustic (r) and caustic (f), for ductile material 1 - brittle material 2 bimaterial plate with $\mathrm{E}_{12}=0.10, \quad v_{1}=v_{2}=0.30, \quad \lambda=0.6966$, $\mathrm{b}_{2}=0.2816 \mathrm{~d}_{2}, \mathrm{c}_{1}=0.151 \mathrm{~d}_{2}, \mathrm{~d}_{1}=0.406 \mathrm{~d}_{2}, \mathrm{c}_{2}=0$ and $\mathrm{d}_{2}=1$.

The relative size of the caustics (r) and (f) depends on the stress-optical constants $c_{r}$ and $c_{f}$ of the two materials of the bi-material plate.

The stress intensity factor $\mathrm{K}_{\mathrm{I}}$ can be experimentally calculated from the maximum, $\mathrm{D}_{\max }$, so diameter of the caustic according to the relation (Papadopoulos 1993) [3]:

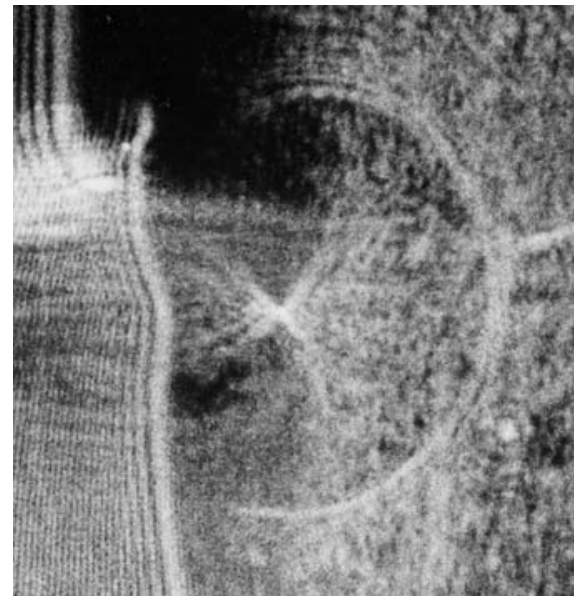

Fig. (7). Experimental caustic (r) at crack-tip of Plexiglas 1 - Lexan 2 bi-material plate.

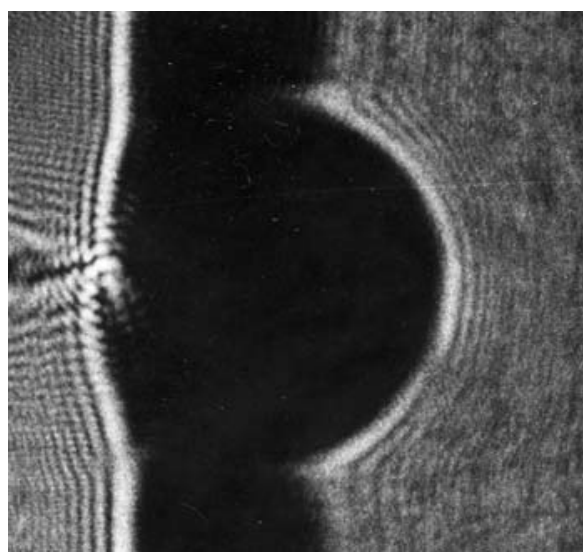

$K_{I}=\frac{0.04668}{z_{0} t \lambda_{m}^{3 / 2} c_{r, t}} D_{\max }^{5 / 2}$

Fig. (8). Experimental caustic (t) at crack-tip of Plexiglas 1 - Lexan 2 bi-material plate.

Fig. (7) presents the experimental reflected caustic (caustic (r)) at the crack-tip of bi-material plate with material 1 (Plexiglas) - material 2 (Lexan). Fig. (8) presents the experimental transmitted caustic (caustic (t)) at the crack-tip for the same bi-material plate of Fig. (7).

\section{Theory of Photoelasticity}

Isochromatic fringes are loci of points with the same value for the difference of the principal stresses or the maximum shear stress. According to the stress optical law, the difference in the principal stresses is given by [24]: 
$\sigma_{1}-\sigma_{2}=2 \tau^{\max }=\frac{N_{c} f_{c}}{t}$

where $N_{C}$ is the isochromatic fringe order, $t$ is the thickness of the specimens and $f_{c}$ is the material fringe value or stressoptical constant, which is given by the relation:

$f_{c}=\frac{E \lambda_{\ell}}{2 v}$

where $\mathrm{E}$ is the elastic modulus, $\lambda_{l}$ is the wave length of the used monochromatic light and $v$ is the Poisson's ratio of the plate material.

From equations (3)-(5) and (25) is obtained:

$r=\left\{\begin{array}{l}\frac{1}{\left.\left[\left(1-\lambda^{2}\right) F(\theta)+F^{\prime \prime}(\theta)\right]^{2}+\right]^{1 / 2}} \\ 4 \lambda^{2}\left(F^{\prime}(\theta)\right)^{2} \\ \frac{N_{c}\left(f_{c}\right)_{1,2}}{t}\end{array}\right\}^{\frac{1}{\lambda-1}}$

with:

$F(\theta)=\alpha_{2} \sin (\lambda+1) \theta+b_{2} \cos (\lambda+1) \theta+$

$c_{2} \sin (\lambda-1) \theta+d_{2} \cos (\lambda-1) \theta$

The relation between the stress-optical constants of the materials 1 and 2 is:

$\left(f_{c}\right)_{2}=\frac{1}{E_{12}} \frac{v_{1}}{v_{2}}\left(f_{c}\right)_{1}$

where $E_{12}=E_{1} / E_{2}$ is the ratio of the elastic modulus of the two materials, $v_{1}$ and $v_{2}$ are the Poisson's ratios of the two materials.

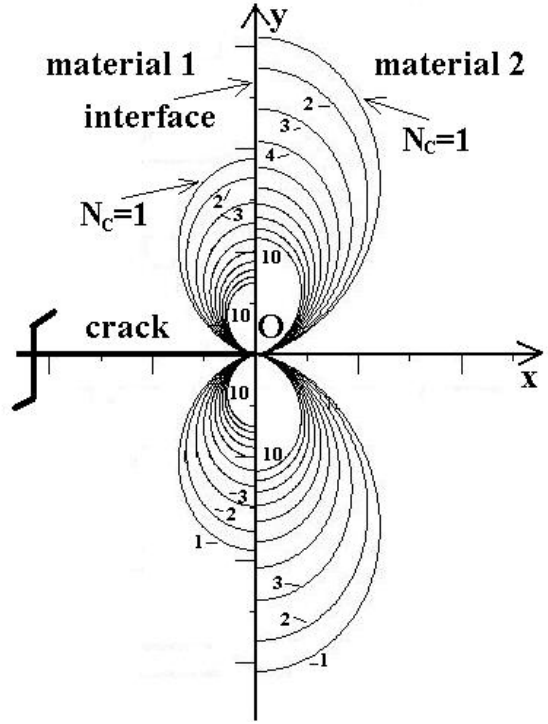

Fig. (9). Isochromatic fringes of order $N_{C}=1 \div 10$ for $\mathrm{E}_{12}=1.2142$, $v_{1}=0.34, v_{2}=0.36$ and $\lambda=0.48$ (Plexiglas $1-$ Lexan 2).

The isochromatic fringes are plotted around the crack-tip by the equation (27) for $\left(f_{c}\right)_{1}=1, t=0.003 \mathrm{~m}, d_{2}=1$. Fig. (9) presents the plotted isochromatic fringes of order $N_{C}=1 \div 10$, for Plexiglas 1 - Lexan 2 bi-material plate, with $\mathrm{E}_{12}=$ $1.2142, v_{1}=0.34, v_{2}=0.36$ and $\lambda=0.48$. It is observed that the branches of the isochromatic fringes, which correspond to the ductile material (material 2), are bigger than the branches corresponding to the brittle material (material 1). This means that the maximum shear stress at the crack-tip is considerable in brittle material (material 1). The jump of the values is exactly placed at the interface.

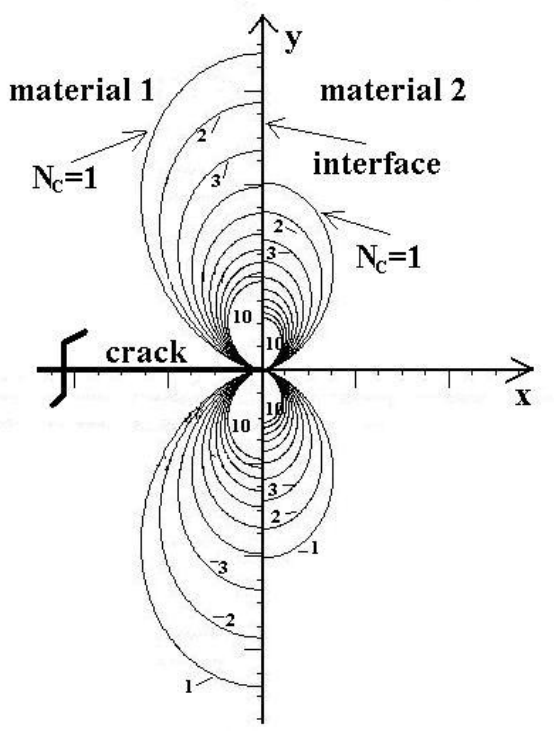

Fig. (10). Isochromatic fringes of order $N_{C}=1 \div 10$ for $\mathrm{E}_{12}=$ $0.82353, v_{1}=0.36, v_{2}=0.34$ and $\lambda=0.5192$ (Lexan 1- Plexiglas 2).

Fig. (10) presents the plotted isochromatic fringes of order $N_{C}=1 \div 10$, for Lexan 1 - Plexiglas 2 bi-material plate, with $\mathrm{E}_{12}=0.82353, v_{1}=0.36, v_{2}=0.34$ and $\lambda=0.5192$.

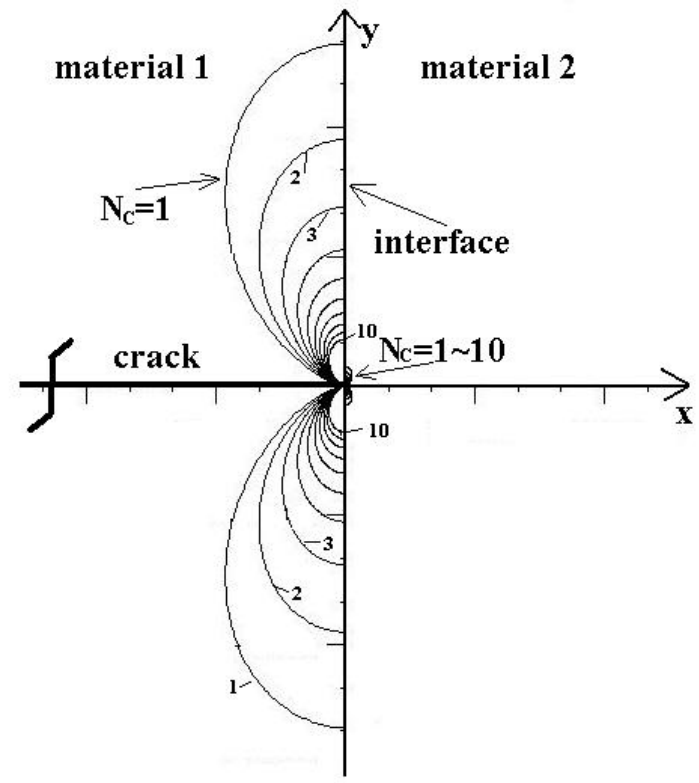

Fig. (11). Isochromatic fringes of order $N_{C}=1 \div 10$ for $\mathrm{E}_{12}=0.336$, $v_{1}=0.36, v_{2}=0.34$ and $\lambda=0.603$ (ductile 1 - brittle 2).

Fig. (11) presents the plotted isochromatic fringes of order $N_{C}=1 \div 10$, for ductile material 1 - brittle material 2 bimaterial plate, with $\mathrm{E}_{12}=0.336, v_{1}=0.36, v_{2}=0.34$ and $\lambda=0.603$.

Fig. (12) presents the plotted isochromatic fringes of order $N_{C}=1 \div 10$, for ductile material 1 - brittle material 2 bimaterial plate, with $\mathrm{E}_{12}=0.10, v_{1}=v_{2}=0.30$ and $\lambda=0.6966$. 


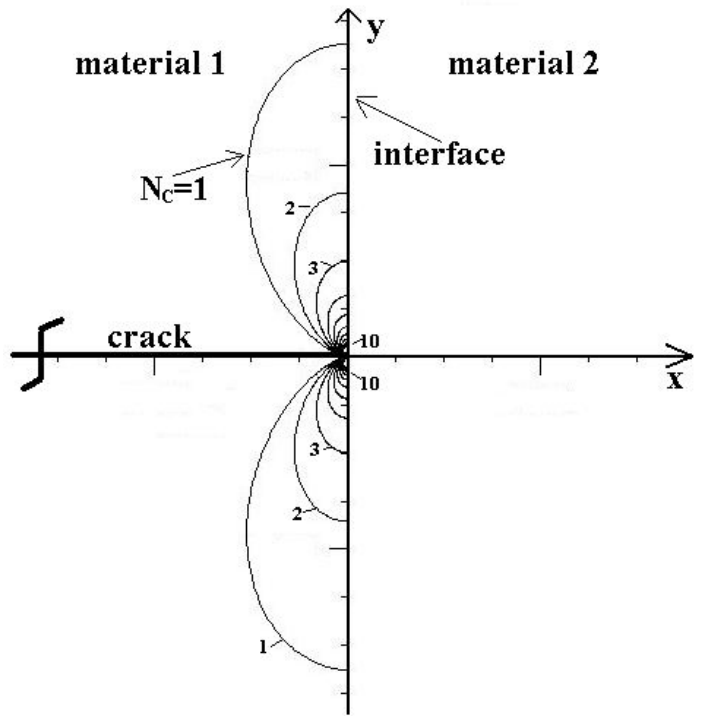

Fig. (12). Isochromatic fringes of order $N_{C}=1 \div 10$ for $\mathrm{E}_{12}=0.10$, $v_{1}=v_{2}=0.30$ and $\lambda=0.6966$ (ductile 1 - brittle 2).

\section{Theory of Isopachic Fringes}

Isopachics fringes are loci of points with the same value for the sum of the principal stresses. The fringe orders $N_{p}$ of isopachic are related to the sum of the principal stresses by [25]:

$\sigma_{1}+\sigma_{2}=\sigma_{r}+\sigma_{\theta}=\frac{N_{p} f_{p}}{t}$

where $N_{p}$ is the order of isopachics, $\mathrm{t}$ is the thickness of the plate and $f_{p}$ is the isopachic fringe constant, which is given by the relation:

$f_{p}=\frac{E \lambda_{\ell}}{2 v}$

where $\mathrm{E}$ is the elastic modulus, $\lambda_{l}$ is the wave length of the used monochromatic light and $v$ is the Poisson's ratio of the plate material.

The sum of the stresses (from equations (3) and (4)) are:

$\sigma_{1}+\sigma_{2}=\sigma_{r}+\sigma_{\theta}=$

$r^{\lambda-1}\left[(\lambda+1)^{2} F(\theta)+F^{\prime \prime}(\theta)\right]$

with:

$F(\theta)=\alpha_{2}|\sin (\lambda+1) \theta|+b_{2}|\cos (\lambda+1) \theta|+$

$c_{2}|\sin (\lambda-1) \theta|+d_{2}|\cos (\lambda-1) \theta|$

$F^{\prime \prime}(\theta)=-\alpha_{2}(\lambda+1)^{2}|\sin (\lambda+1) \theta|-$

$b_{2}(\lambda+1)^{2}|\cos (\lambda+1) \theta|-$

$c_{2}(\lambda-1)^{2}|\sin (\lambda-1) \theta|-d_{2}(\lambda-1)^{2}|\cos (\lambda-1) \theta|$

By substituting the equations (32)-(34) into equation (30) is obtained:

$r=\left\{\frac{1}{(\lambda+1)^{2} F(\theta)+F^{\prime \prime}(\theta)} \frac{N_{p}\left(f_{p}\right)_{1,2}}{t}\right\}^{\frac{1}{\lambda-1}}$ with:

$\left(f_{p}\right)_{2}=\frac{1}{E_{12}} \frac{v_{1}}{v_{2}}\left(f_{p}\right)_{1}$

where $\left(f_{p}\right)_{1,2}$ are the isopachic fringe constants of the materials 1 and 2 of the bi-material plate, respectively.

The isopachic fringes are plotted around the crack-tip by the equation (34) for $\left(f_{p}\right) 1=1, t=0.003 m, d_{2}=1$. Fig. (13) presents the plotted isopachic fringes of order $N_{p}=1 \div 10$, for Plexiglas 1 - Lexan 2 bi-material plate, with $\mathrm{E}_{12}=1.2142$, $v_{1}=0.34, v_{2}=0.36$ and $\lambda=0.48$.

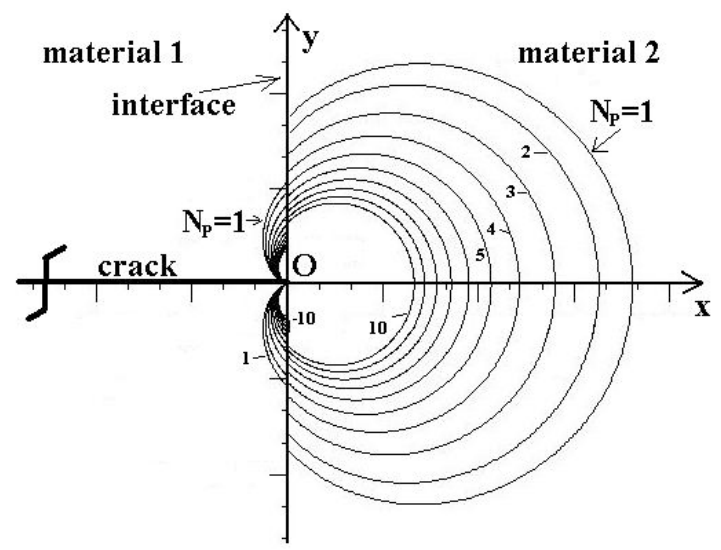

Fig. (13). Isopachic fringes of order $N_{p}=1 \div 10$ for $\mathrm{E}_{12}=1.2142, v_{1}=$ $0.34, v_{2}=0.36$ and $\lambda=0.48$ (Plexiglas 1 - Lexan 2).

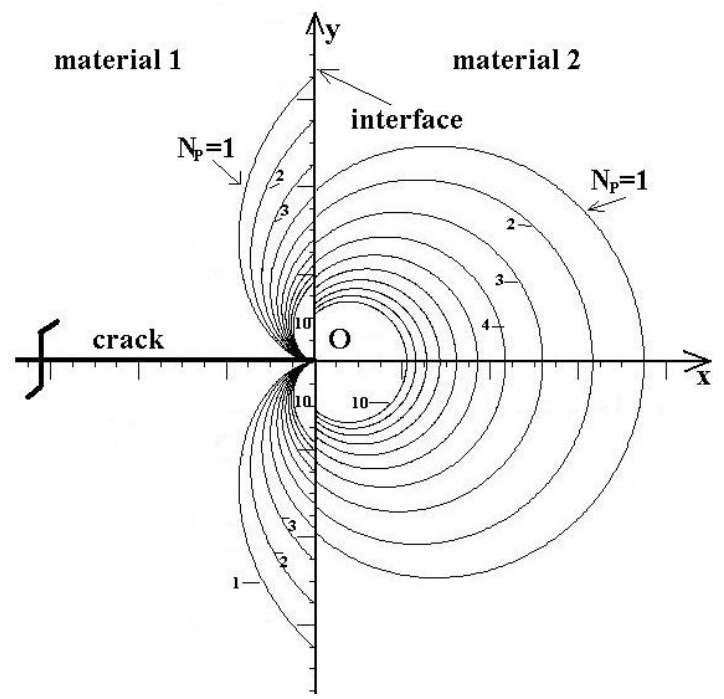

Fig. (14). Isopachic fringes of order $N_{p}=1 \div 10$ for $\mathrm{E}_{12}=0.82353$, $v_{1}=0.36, v_{2}=0.34$ and $\lambda=0.5192$ (Lexan 1- Plexiglas 2).

Fig. (14) presents the plotted isopachic fringes of order $N_{p}=1 \div 10$, for Lexan 1 - Plexiglas 2 bi-material plate, with $\mathrm{E}_{12}=0.82353, v_{1}=0.36, v_{2}=0.34$ and $\lambda=0.5192$.

Fig. (15) presents the plotted isopachic fringes of order $N_{p}=1 \div 10$, for ductile material 1 - brittle material 2 bimaterial plate, with $\mathrm{E}_{12}=0.336, v_{1}=0.36, v_{2}=0.34$ and $\lambda=0.603$.

Fig. (16) presents the plotted isopachic fringes of order $N_{p}=1 \div 10$, for ductile material 1 - brittle material 2 bimaterial plate, with $\mathrm{E}_{12}=0.10, v_{1}=v_{2}=0.30$ and $\lambda=0.6966$. 


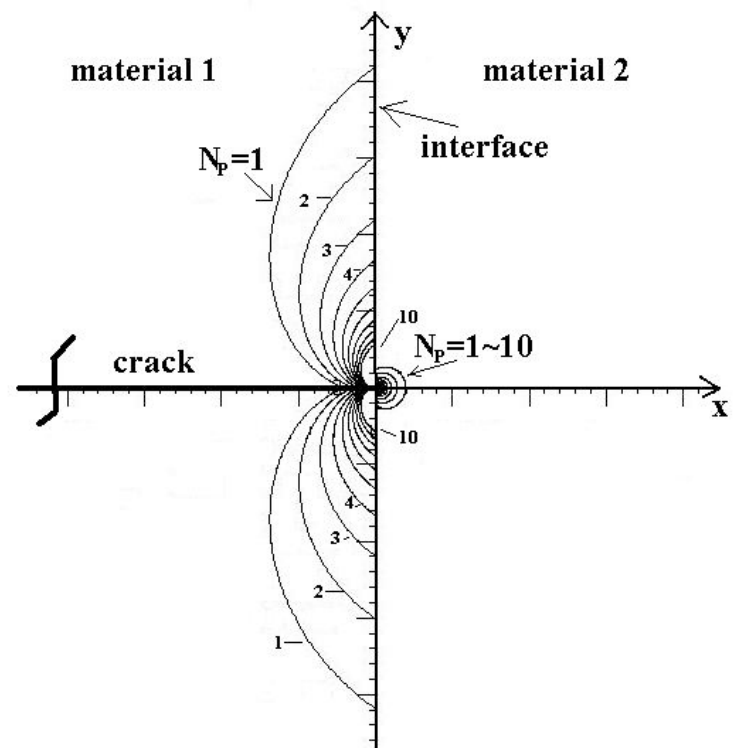

Fig. (15). Isopachic fringes of order $N_{p}=1 \div 10$ for $\mathrm{E}_{12}=0.336, v_{1}=$ $0.36, v_{2}=0.34$ and $\lambda=0.603$ (ductile 1- brittle 2).

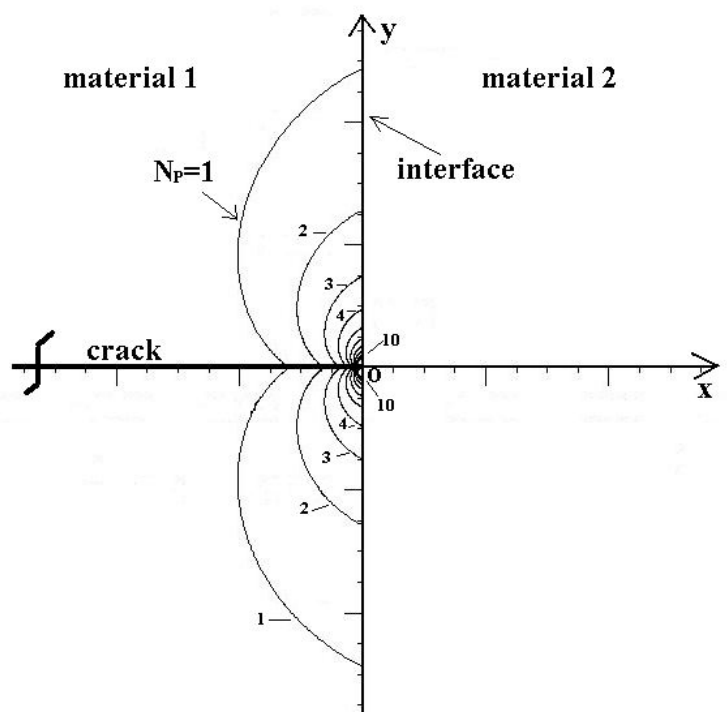

Fig. (16). Isopachic fringes of order $N_{p}=1 \div 10$ for $\mathrm{E}_{12}=0.10, v_{1}=$ $v_{2}=0.30$ and $\lambda=0.6966$ (ductile 1 - brittle 2 ).

\section{Principal Stresses Estimation from the Isochromatic and Isopachic Fringes}

The principal stresses can be estimated from the system of isochromatic and isopachic fringes (Eqs. (25), (30)). The solution of the system is valid at the cross points of the isochromatic and isopachic fringes (Fig. (17)). Fig. (17) presents the overlapping of isochromatic and isopachic fringes by Eqs. (27) and (35), for Lexan 1-Plexiglas 2 bimaterial plate with $\mathrm{E}_{12}=0.82353, v_{1}=0.36, v_{2}=0.34, \lambda=0.5192$, $\mathrm{t}=0.003$ and $\mathrm{d}_{2}=1\left(\mathrm{~d}_{2}\right.$ is an arbitrary constant which represents the tensile load of the plate). Fig. (18) presents experimentally the overlapping of isochromatic and isopachic fringes for $E_{12}=1$ (one material, Lexan). At the cross points of the fringes, the principal stresses can be calculated by the Eqs. (25) and (30). Also, at the crack tip, the caustics (r) and (f) were taken from which the stress intensity factor $\mathrm{K}_{\mathrm{I}}$ can be calculated.

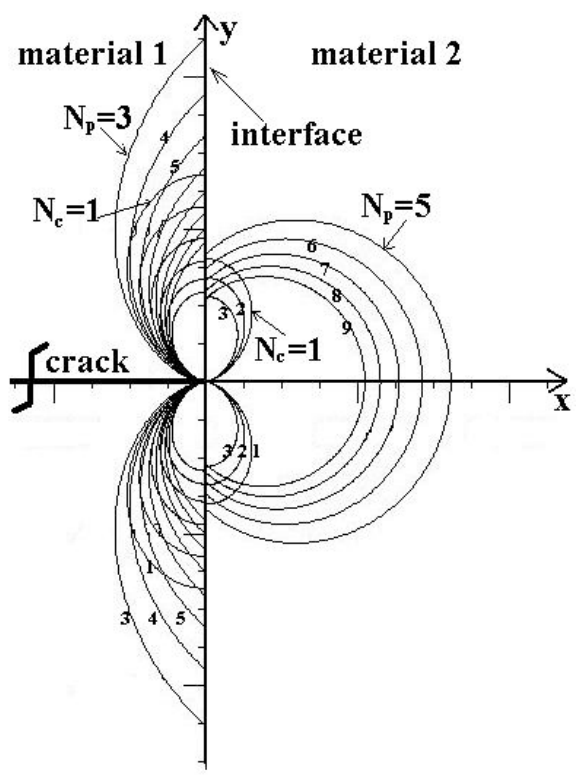

Fig. (17). Overlapping of Isochromatic $\left(\mathrm{N}_{\mathrm{c}}\right)$ and Isopachic $\left(\mathrm{N}_{\mathrm{p}}\right)$ fringes.

From the solution of the equations (25) and (30) system, the principal stresses are obtained:

$$
\begin{aligned}
& \sigma_{1}=\frac{\sigma_{r}+\sigma_{\theta}}{2}+\frac{1}{2} \sqrt{\left(\sigma_{r}-\sigma_{\theta}\right)^{2}+4 \tau_{r \theta}^{2}}= \\
& \frac{N_{p}\left(f_{p}\right)_{1,2}+N_{c}\left(f_{c}\right)_{1,2}}{2 t} \\
& \sigma_{2}=\frac{\sigma_{r}+\sigma_{\theta}}{2}-\frac{1}{2} \sqrt{\left(\sigma_{r}-\sigma_{\theta}\right)^{2}+4 \tau_{r \theta}^{2}}= \\
& \frac{N_{p}\left(f_{p}\right)_{1,2}-N_{c}\left(f_{c}\right)_{1,2}}{2 t}
\end{aligned}
$$

By substituting the stresses from the Eqs. (3)-(5) into Eqs. (37), (38) the contour curves of the principal stresses, around the crack-tip, are obtained:

$$
\begin{aligned}
& r_{\sigma_{1}}=\left\{\frac{2 \sigma_{1}}{\left[\begin{array}{l}
\left.(1+\lambda)^{2} F(\theta)\right]+\left[\begin{array}{l}
{\left[\left(1-\lambda^{2}\right) F(\theta)\right.} \\
\left.+F^{\prime \prime}(\theta)\right]^{2}+ \\
+F^{\prime \prime}(\theta)
\end{array}\right] \\
4 \lambda^{2}\left(F^{\prime}(\theta)\right)^{2}
\end{array}\right]}\right\}^{\frac{1}{\lambda-1}} \\
& r_{\sigma_{2}}=\left\{\begin{array}{l}
2 \sigma_{2} \\
{\left[\begin{array}{l}
\left.(1+\lambda)^{2} F(\theta)\right]-\left[\begin{array}{l}
{\left[\left(1-\lambda^{2}\right) F(\theta)\right.} \\
\left.+F^{\prime \prime}(\theta)\right]^{2}+ \\
+F^{\prime \prime}(\theta)
\end{array}\right] \\
4 \lambda^{2}\left(F^{\prime}(\theta)\right)^{2}
\end{array}\right]}
\end{array}\right\}
\end{aligned}
$$

or: 


$$
\begin{aligned}
& r_{\sigma_{1}}=\left\{\frac{\frac{N_{p}\left(f_{p}\right)_{1,2}+N_{c}\left(f_{c}\right)_{1,2}}{t}}{\left[\begin{array}{l}
\left.(1+\lambda)^{2} F(\theta)\right]+\left[\begin{array}{l}
{\left[\left(1-\lambda^{2}\right) F(\theta)\right.} \\
\left.+F^{\prime \prime}(\theta)\right]^{2}+ \\
+F^{\prime \prime}(\theta)
\end{array}\right] \\
4 \lambda^{2}\left(F^{\prime}(\theta)\right)^{2}
\end{array}\right]}\right\}^{\frac{1}{\lambda-1}} \\
& r_{\sigma_{2}}=\left\{\frac{\frac{N_{p}\left(f_{p}\right)_{1,2}-N_{c}\left(f_{c}\right)_{1,2}}{t}}{\left[\begin{array}{l}
\left.(1+\lambda)^{2} F(\theta)\right]-\left[\begin{array}{l}
{\left[\left(1-\lambda^{2}\right) F(\theta)\right.} \\
\left.+F^{\prime \prime}(\theta)\right]^{2}+ \\
+F^{\prime \prime}(\theta)
\end{array}\right] 1 / 2 \\
\left.4 \lambda^{2}(\theta)\right)^{2}
\end{array}\right]}\right\}^{\frac{1}{\lambda-1}}
\end{aligned}
$$

with:

$$
\begin{aligned}
& F(\theta)=\alpha_{2}|\sin (\lambda+1) \theta|+b_{2}|\cos (\lambda+1) \theta|+ \\
& c_{2}|\sin (\lambda-1) \theta|+d_{2}|\cos (\lambda-1) \theta| \\
& F^{\prime}(\theta)=\alpha_{2}(\lambda+1)|\cos (\lambda+1) \theta|- \\
& b_{2}(\lambda+1)|\sin (\lambda+1) \theta|+c_{2}(\lambda-1)|\cos (\lambda-1) \theta|- \\
& d_{2}(\lambda-1)|\sin (\lambda-1) \theta| \\
& F^{\prime \prime}(\theta)=-\alpha_{2}(\lambda+1)^{2}|\sin (\lambda+1) \theta|- \\
& b_{2}(\lambda+1)^{2}|\cos (\lambda+1) \theta|-c_{2}(\lambda-1)^{2}|\sin (\lambda-1) \theta| \\
& -d_{2}(\lambda-1)^{2}|\cos (\lambda-1) \theta|
\end{aligned}
$$

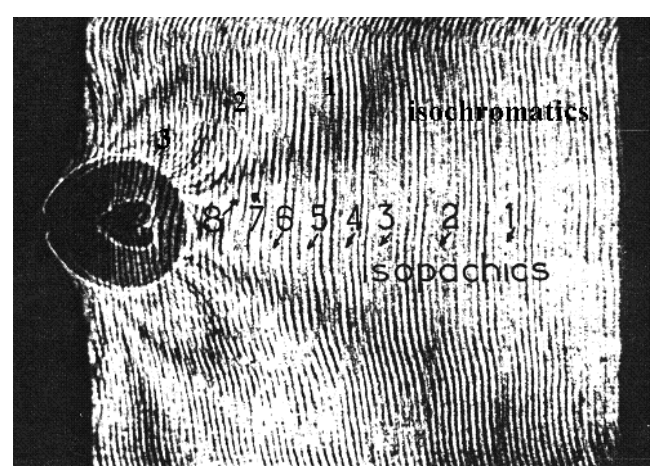

Fig. (18). Experimentally overlapping of Isochromatic and Isopachic fringes and caustics at the crack tip in one material (Lexan) plate.

Fig. (19) presents the contour curves of the principal stresses $\sigma_{1}$ and $\sigma_{2}$ around the crack-tip for Lexan 1-Plexiglas 2 bi-material plate with $\mathrm{E}_{12}=0.82353, v_{1}=0.36, v_{2}=0.34$, $\lambda=0.5192, \mathrm{~d}_{2}=1$ and $\mathrm{t}=0.003$ for isopachic fringe order $\mathrm{N}_{\mathrm{p}=1}$ and isochromatic fringe orders $\mathrm{N}_{\mathrm{c}}=3,4$. Fig. (20) presents the contour curves of the principal stresses $\sigma_{1}$ and $\sigma_{2}$ around the crack-tip for the same bi-material with $\mathrm{N}_{\mathrm{p}=2}$ and $\mathrm{N}_{\mathrm{c}}=3,4$ and Fig. (21) presents the contour curves of the principal stresses $\sigma_{1}$ and $\sigma_{2}$ around the crack-tip for the same bi-material with $\mathrm{N}_{\mathrm{p}=} 5$ and $\mathrm{N}_{\mathrm{c}}=3,4$. A jump of values of principal stresses are appeared at the bi-material interface.

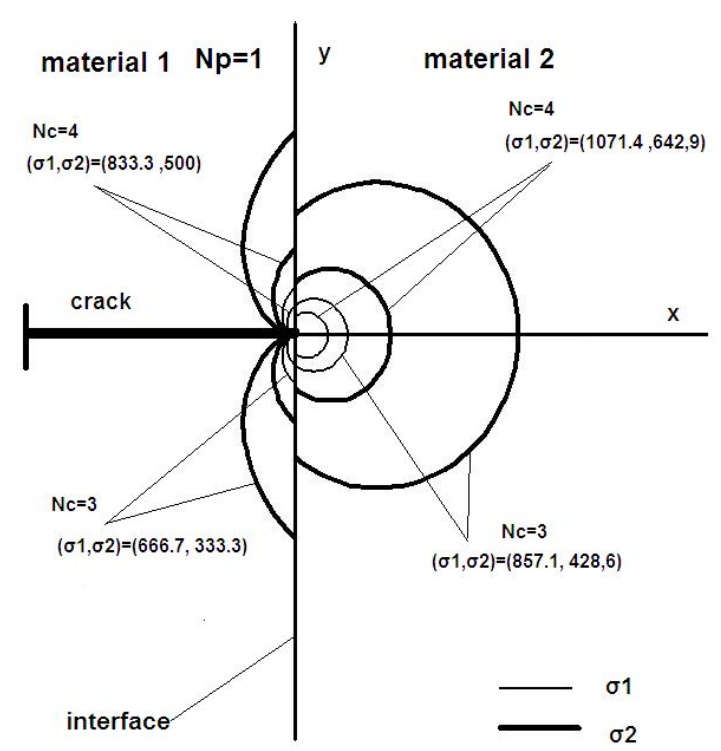

Fig. (19). Contour curves of principal stresses around the crack-tip for $N_{p}=1$ and $N_{C}=3,4$.

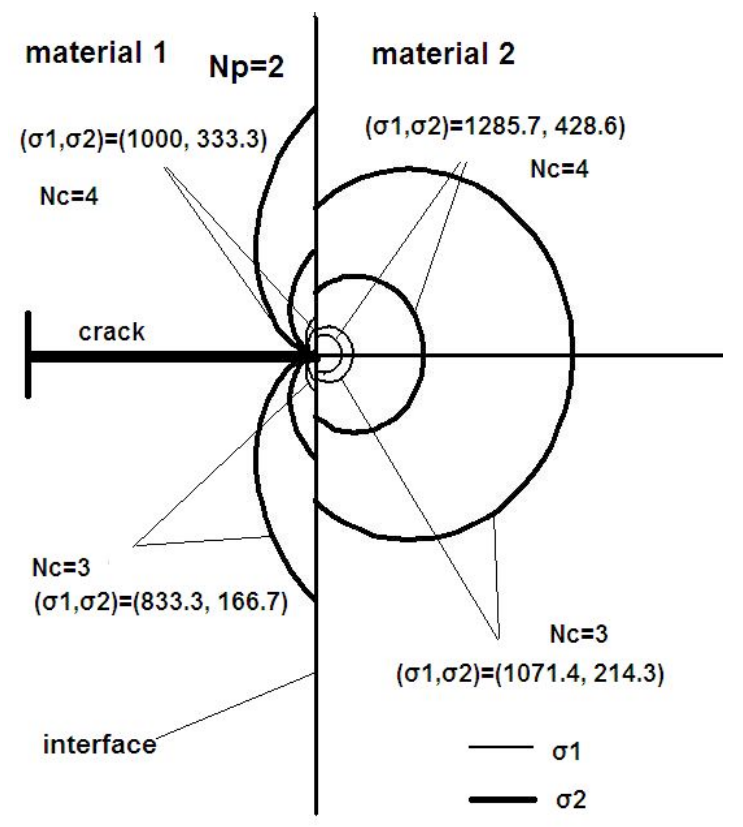

Fig. (20). Contour curves of principal stresses around the crack-tip for $N_{p}=2$ and $N_{C}=3,4$.

\section{CONCLUSIONS}

According to the above study it is concluded that the stress state at the crack-tip can be considered by the method of caustics, while the stress state far from the crack-tip can be considered by the methods of photoelasticity and isopachics. The stress intensity factor $\mathrm{K}_{\mathrm{I}}$ can be calculated from the diameters of the crack-tip caustics. The contour curves of principal stresses can be plotted around the cracktip at the interface of the bi-material from the overlapping of the isochromatic and isopachic fringes. Also, the distribution of the principal stresses close and far from the crack-tip can be experimentally considered by the methods of photoelasticity and isopachics. 


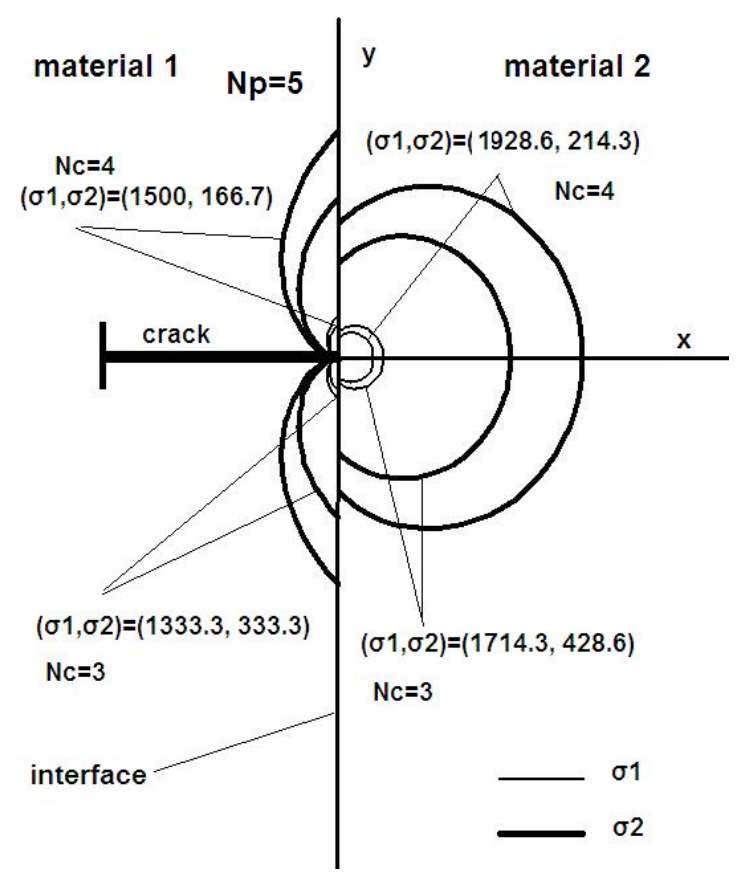

Fig. (21). Contour curves of principal stresses around the crack-tip for $N_{p}=5$ and $N_{C}=3,4$.

The caustics theory and the isochromatic and isopachic fringes at a bi-material interface crack-tip was developed in Refs [22,23]. In this work the evaluation of principal stresses and its contour at a bi-material interface crack-tip were developed by the combination of isochromatic and isopachic fringes. The principal stresses were calculated at cross points of the isochromatic and isopachic fringes. So, the principal stresses can experimentally be calculated from the photograph of Fig. (18).

Fig. (18) illustrates experimentally superposition of isochromatic and isopachic fringes and the caustic at the cracktip. The stress intensity factor at crack-tip and far from crack-tip and the principal stresses can calculated experimentally. The picture of Fig. (18) was generated by the overlapping of three photographs. The first photograph was taken from the unloading specimen. The second photograph was taken from the loading specimen in that caustic was formed at the crack-tip. The third photograph was taken from the loading specimen in which isochromatic fringes were formed around the crack-tip. By the superposition of these three photographs, the photograph of Fig. (18) was formed. The isopachic fringes are the moiré which is formed by the interference fringes of the first and second photographs which are dependent on the variation of the specimen thickness [25].

\section{REFERENCES}

[1] P. Manogg, "Anwendung der Schattenoptik zur Untersuchung des Zerreissvorgangs von Platten". Dissertation 4/64, Universitaet Freiburg, 1964.

[2] P.S. Theocaris, "Local yielding around a crack-tip in Plexiglas",. Journal of Applied Mechanics, vol.37, pp. 409-415,1970.
[3] G.A. Papadopoulos, FRACTURE MECHANICS, The Experimental Method of Caustics and the Det.-Criterion of Fracture (G.A. Papadopoulos Ed.), Springer-Verlag, London, 1993.

[4] P.S. Theocaris and G.A. Papadopoulos, "Stress intensity factor from reflected caustics in birefringent plates with crack", J. Strain Analysis, vol.16, pp.29-36, 1981.

[5] A.R. Zak and M.L. Williams, "Crack point stress singularities at a bimaterial interface", Journal of Applied Mechanics, vol. 30, pp.142-143, 1963.

[6] M.L. Williams, "Surface stress singularities resulting from various boundary conditions in angular corners of plates under bending", Proceedings, First U.S.National Congress of Applied Mechanics, ASME, 1952; pp.325-329.

[7] M.L. Williams, "Stress singularities resulting from various boundary conditions in angular corners of plates in extension", Journal of Applied Mechanics 19, Trans. ASME, vol. 74, pp.526528,1952

[8] M.L. Williams, "On the stress at the base of a stationary crack", Journal of Applied Mechanics 24, Trans. ASME, vol. 79, pp.109114,1957

[9] M.L.Williams, "The stresses around a fault or crack in dissimilar media", Bulletin of the Seismological Society of America, vol. 49, pp.199-204, 1959

[10] J.W. Dally and T. Kobayashi, "Crack arrest in duplex specimens", Int. J. Solids and Structures, vol.14, pp.121-126, 1978.

[11] P.S. Theocaris, "The Mesophase Concept in Composites", (P.S Theocaris Ed.), Springer-Verlag, Berlin Heidelberg, 1987.

[12] P.S. Theocaris and J. Milios, "Dynamic crack propagation in composites", Int. J. Fracture, vol.16, pp.31-51, 1980.

[13] P.S. Theocaris and J. Milios, "Crack propagation velocities in biphase plates under static and dynamic loading", Engineering Fracture Mechanics, vol.13, pp.559-569, 1979.

[14] P.S. Theocaris and J. Milios, "Crack arrest at a bimaterial interface", Int. J. Solids Structures, vol. 17, pp.217-230, 1981.

[15] P.S. Theocaris, M. Siarova and G.A. Papadopoulos, "Crack propagtion and bifurcation in fiber-composite models: I Soft-hardsoft sequence of phases", J. Reinforced Plastics and Composites, vol. 5, pp.23-50, 1986

[16] P.S. Theocaris and G.A. Papadopoulos, "Crack propagation and bifurcation in fiber-composite models II: Hard-soft-hard sequence of phases", Journal of Reinforced Plastics and Composites, vol. 5, pp.120-140, 1986.

[17] E.E. Gdoutos, "Failure of a bimaterial plate with a crack at an arbitrary angle to the interface", Fiber Science and Technology, vol.15, pp.27-40, 1981.

[18] E.E. Gdoutos and A. Giannakopoulou, "Stress and failure analysis of brittle matrix composites. Part I: Stress analysis", International Journal of Fracture, vol. 98, pp.263-277, 1999.

[19] E.E. Gdoutos, A. Giannakopoulou and D.A. Zacharopoulos, "Stress and failure analysis of brittle matrix composites. Part II: failure analysis", International Journal of Fracture,vol. 98, pp.279-291, 1999.

[20] E.N.Theotokoglou, G.J. Tsamasphyros and C.P. Spyropoulos, "Photoelastic study of a crack approaching the bonded half-plates interface", Engineering Fracture Mechanics, vol. 34, pp.31-42, 1989.

[21] C.P. Spyropoulos, E.N. Theotokoglou and G.J. Tsamasphyros, "Evaluation of the stress intensity factors for a crack approaching the bonded half-plates interface from isopachics", Acta Mechanica, vol.81, pp.75-89, 1990.

[22] G.A. Papadopoulos, "Crack-tip caustics at a bi-material interface", International journal of Fracture, vol. 98, pp.329-342, 1999.

[23] G.A. Papadopoulos and N. Moscos,Crack-tip isochromatic and isopachic fringes at a bi-material interface", International journal of Fracture, vol.141, pp.327-332, 2006.

[24] M.M. Frocht, Photoelasticity. John Willey, New York,1948

[25] A.J. Durelli and W.F. Riley, Introduction to Photomechanics. Prentice-Hall Inc./Englewood Cliffs NI, USA, 1965. 